\title{
Propofol may increase caspase and MAPK pathways, and suppress the Akt pathway to induce apoptosis in MA-10 mouse Leydig tumor cells
}

\author{
FU-CHI KANG $^{1 *}$, SHU-CHUN WANG $^{2 *}$, EDMUND CHEUNG SO $^{3,4}$, MING-MIN CHANG ${ }^{2}$, KAR-LOK WONG $^{3}$, \\ $\mathrm{KA} \mathrm{SHUN} \mathrm{CHENG}^{3,5}$, YUNG-CHIA $\mathrm{CHEN}^{6}$ and BU-MIIN HUANG ${ }^{2,7}$ \\ ${ }^{1}$ Department of Anesthesia, Chi Mei Medical Center, Chiali, Tainan 70722; ${ }^{2}$ Department of Cell Biology and Anatomy, \\ College of Medicine, National Cheng Kung University, Tainan 70101; ${ }^{3}$ Department of Anesthesia, China Medical University, \\ Taichung 40406; ' Department of Anesthesia, An Nan Hospital, China Medical University, Tainan 70709, Taiwan, R.O.C.; \\ ${ }^{5}$ Department of Anesthesiology, The Qingdao University Yuhuangding Hospital, Yantai, Shandong 261400, P.R. China; \\ ${ }^{6}$ Department of Anatomy, School of Medicine, Kaohsiung Medical University, Kaohsiung 80807; \\ ${ }^{7}$ Department of Medical Research, China Medical University Hospital, China Medical University,
} Taichung 40406, Taiwan, R.O.C.

Received October 6, 2018; Accepted April 17, 2019

DOI: $10.3892 /$ or.2019.7129

\begin{abstract}
In the western world, there is an increasing trend of occurrence in testicular cancer. Treatment of malignant testicular cancer is primarily combined surgery with various chemical drugs. Propofol has been frequently used as an anesthetic and sedative induction agent, which could modulate different $\gamma$-aminobutyric acid receptors in the central nervous system. Studies demonstrated that propofol activates endoplasmic reticulum stress to induce apoptosis in lung cancer. However, it remains elusive whether propofol regulates caspase and/or mitogen-activated protein kinase (MAPK) pathways to induce apoptosis in Leydig tumor cells. In the present study, MA-10 mouse Leydig tumor cells were treated with propofol, and possible signal pathways associated with apoptosis were investigated. Results demonstrated that increasing dosage of propofol (300-600 $\mu \mathrm{M})$ for $24 \mathrm{~h}$ significantly decreased cell viability in MA-10 cells $(\mathrm{P}<0.05)$. In flow cytometry analysis, the amount of sub-G1 phase cell numbers in MA-10 cells was
\end{abstract}

Correspondence to: Professor Bu-Miin Huang, Department of Cell Biology and Anatomy, College of Medicine, National Cheng Kung University, 1 University Road, Tainan 70101, Taiwan, R.O.C.

E-mail: bumiin@mail.ncku.edu.tw

Dr Yung-Chia Chen, Department of Anatomy, School of Medicine, Kaohsiung Medical University, 100 Shiquan 1st Road, Kaohsiung 80807, Taiwan, R.O.C.

E-mail: yungchia@kmu.edu.tw

*Contributed equally

Key words: Leydig tumor cell, propofol, caspase cascade, mitogen-activated protein kinase pathway, Akt pathway, apoptosis significantly increased by propofol $(\mathrm{P}<0.05)$. Additionally, Annexin V/propidium iodide double staining further confirmed that propofol could induce MA-10 cell apoptosis. Furthermore, cleaved caspase-8, -9 and -3 , and/or poly(ADP-ribose) polymerase were significantly activated following treatment of propofol in MA-10 cells. In addition, c-Jun N-terminal kinase, extracellular signal-regulated kinase $1 / 2$, and p38 were significantly activated by propofol in MA-10 cells $(\mathrm{P}<0.05)$, indicating that propofol may induce apoptosis through the MAPK pathway. Additionally, propofol diminished the phosphorylation of Akt to activate apoptosis in MA-10 cells. In conclusion, propofol may induce MA-10 cell apoptosis by activating caspase and MAPK pathways, and inhibiting the Akt pathway in MA-10 cells, demonstrating that propofol may be a potential anticancer agent against Leydig cell cancer.

\section{Introduction}

Propofol (2,6-disopropylphenol) is a short-acting drug, which has been extensively used as a sedative and anesthetic induction drug prior to medical procedures, which could modulate the different $\gamma$-aminobutyric acid receptors in the central nervous system (1). It has been indicated that the use of sedative techniques could affect long-term outcome following cancer surgery, including propofol, which has potential to impede metastasis and to activate apoptosis in cancer cells (2). Besides, previous studies demonstrated that propofol has antitumor effects inhibiting invasion or proliferation in ovarian cancer cells and osteosarcoma cells $(3,4)$. A number of reports demonstrated that propofol could induce apoptosis in different cancer cells, including pancreatic cancer (5), lung cancer (6,7), epithelial ovarian cancer (8) and hepatocarcinoma (9). Thus, propofol has the ability to be a therapeutic drug for malignancies.

The control of cell number is important in tissue homeostasis, and its dysregulation could give rise to the occurrence 
of tumors, which could be regulated by cell death, proliferation and differentiation (10). A previous study demonstrated that cancer cells exhibit different characteristics progressing from normal cells to tumor cells, which include tissue invasion and metastasis, unlimited replicative capability, self-sufficiency in growth signals, avoidance of apoptosis, continued angiogenesis, and resistance to antigrowth signals (11), and the majority of anticancer therapies are against these properties $(10,11)$. Notably, when cells experience environmental stresses or the stimulation of intracellular signals, cell death may occur (12). Cell death is classified in three categories from morphological appearance, including autophagy, necrosis and apoptosis (13). Apoptosis and autophagy are types of programmed cell death $(12,13)$. Autophagy is contradictory for cancer cells with pro-survival or pro-death roles (14). Compared with apoptosis, necrosis is a procedure of cell death in an unregulated manner resulting from severe insults or adverse conditions (15). Therefore, the induction of apoptosis could be a beneficial therapy for patients with cancer. Apoptosis in cells consistently features cell shrinking, nuclear condensation and then fragmentation, membrane blebbing and the formation of apoptotic bodies from the separation of cellular components (16).

There are two major pathways in apoptosis: Extrinsic pathway and intrinsic pathways (17). Extrinsic pathways, also termed death receptor pathways, begin with the activation of death receptors by pro-apoptotic ligands, including Fas ligand, tumor necrosis factor- $\alpha$ (TNF- $\alpha$ ) and TNF superfamily member $10(17,18)$. Following ligand binding, intracellular death domains of these receptors bind to Fas-associated death domain, which causes the recruitment of death-induced signaling complex and the activation of caspase- 8 to trigger downstream effector caspases, including caspase-3 and -7 (18). An intrinsic pathway involves mitochondrial and endoplasmic reticulum pathways. It has been demonstrated that the mitochondrial pathway could be triggered by ultraviolet radiation, chemotherapeutic agents and growth factor withdrawal, resulting in the release of cytochrome $c$ from mitochondrial intermembrane space to cytosol (19). Cytochrome $c$ binds to apoptotic peptidase activating factor-1 to recruit pro-caspase-9 forming apoptosome to cleave caspase-9, and then the active caspase- 9 activates caspase- 3 to orchestrate apoptosis (20). The intrinsic and extrinsic pathways induce poly(ADP-ribose) polymerase (PARP) cleavage following activating downstream caspase effectors, and the cleaved-PARP impedes DNA repair (17).

The mitogen-activated protein kinase (MAPK) pathway serves key roles in cancer development, which also regulates cell growth, proliferation, differentiation, migration and apoptosis (21). MAPKs, including extracellular signal-regulated kinase 1/2 (ERK1/2), c-Jun N-terminal kinase (JNK) and p38, are protein-serine/threonine kinases, which could be activated through a cascade of phosphorylation events and regulate cell fate $(22,23)$.

Akt signaling is a pro-survival pathway, which inhibits apoptotic signal cascades and activates pro-survival signal (24). Akt signaling inhibits a number of pro-apoptotic B-cell lymphoma-2 (Bcl-2) family members, including Bcl-2 associated agonist of cell death, Bcl-2-associated $\mathrm{X}$ and $\mathrm{Bcl}-2$ like 11 (25). Akt also positively regulates anti-apoptotic pathways to induce the nuclear factor- $\kappa \mathrm{B}$ transcription factor, promoting anti-apoptotic genes, including Bcl-2 and Bcl-extra large $(24,25)$. Numerous studies demonstrated that the suppression of Akt prompts apoptosis in human testicular germ tumor cells (24-26).

Testicular cancer is a cancer type that develops in the testis, which is primarily classified into two categories: Germ cell tumor; and stromal tumor (27). Leydig cell tumor types are the most common form of stromal tumors with a significantly increasing incidence, and $10 \%$ of Leydig cell tumor cases are malignant; however, this has not been clearly documented (28). Malignant Leydig cell tumors do not respond to irradiation and chemotherapy (29). Thus, it's important to determine an improved therapeutic method for Leydig cell tumors (29). The majority of the studies demonstrated that propofol induces apoptosis resulting in beneficial therapy for patients with different cancer types (3-5). Therefore, whether propofol promotes apoptosis in MA-10 cells to provide a potential antitumor therapy was investigated.

\section{Materials and methods}

Chemicals. Propofol (cat. no. 1572503; 0.962 g/ml), MTT (cat. no. M5655), penicillin-streptomycin, propidium iodide (PI; cat. no. P4170), RNase A (cat. no. R6513), ethylenediaminetetraacetic acid (EDTA; cat. no. E5134), Triton X-100 (cat. no. T8787), sodium orthovanadate (cat. no. S6508), Waymouth MB 752/1 medium (cat. no. W1625), monoclonal antibody against $\beta$-actin (cat. no. A5441; $1: 8,000$ ) and $30 \%$ acrylamide/Bis-acrylamide solution (cat. no. A3574) were purchased from Sigma-Aldrich (Merck KGaA, Darmstadt, Germany). DS (cat. no. 822050), EGTA (cat. no. L808635342), Tween-20 (cat. no. 817072) and dimethyl sulfoxide (DMSO; cat. no. 102952) were purchased from Merck KGaA. Dulbecco's modified Eagle medium/F12 (cat. no. 12400-024), trypsin-EDTA (cat. no. 15400-054) and fetal bovine serum (FBS; cat. no. 10437-028) were purchased from Gibco (Thermo Fisher Scientific Inc., Waltham, MA, USA). Tris base (cat. no. 4019-06), potassium chloride (cat. no. 3040-01), glycine (cat. no. 4059-06) 4-(2-hydroxyethyl)-1-piperazineethanesulfonic acid (cat. no. 4018-04) and sodium chloride ( $\mathrm{NaCl}$; cat. no. 3624-05) were purchased from J.T.Baker (Avantor Performance Materials, Center Valley, PA, USA). An Annexin V-fluorescein isothiocyanate (FITC) apoptosis detection kit (cat. no. AVK050) was purchased from Strong Biotech Corporation (Taipei, Taiwan). A Micro BCA protein assay kit (cat. no. 23235) was purchased from Thermo Fisher Scientific Inc. An Enhanced chemiluminescence detection kit (cat. no. WBKLS050) was purchased from EMD Millipore (Billerica, MA, USA). Donkey anti-rabbit and anti-mouse IgG conjugated with horseradish peroxidase (HRP) were purchased from PerkinElmer, Inc. (Waltham, MA, USA). Polyclonal antibodies against cleaved caspase-8 (cat. no. 9429; 1:1,000), cleaved caspase-9 (cat. no. 9509; 1:1,000), cleaved PARP (cat. no. 9544; 1:1,000), phospho-ERK1/2 (cat. no. 9101; 1:4,000), ERK1/2 (cat. no. 9102; 1:4,000), phospho-JNK (cat. no. 9251; 1:2,000), JNK (cat. no. 9252; 1:2,000), phospho-p38 MAPK (cat. no. 9215; 1:4,000), p38 MAPK (cat. no. 9212; 1:4,000), phospho-mechanistic target of rapamycin kinase (mTOR; cat. no. 2971; 1:2,000), mTOR (cat. no. 2983; 1:2,000), phospho-Akt (cat. no. 9271; 1:4,000) and Akt (cat. no. 9272; 1:4,000) were purchased from Cell Signaling Technology, 
Inc. (Danvers, MA, USA). Isoton II (cat. no. 8546719) was purchased from Beckman Coulter, Inc. (Brea, CA, USA). Monoclonal antibody against cleaved caspase-3 (cat. no. 9664; 1:1,000) was purchased from Cell Signaling Technology, Inc.

Cell culture. The MA-10 cell line was provided by Dr. Mario Ascoli (Department of Obstetrics and Gynecology, University of Iowa, Iowa City, IA, USA), which is a mouse Leydig tumor cell line cultured in the Waymouth medium containing $10 \%$ FBS. MA-10 cells were regularly maintained in a humidified atmosphere incubator containing $5 \% \mathrm{CO}_{2}$ at $37^{\circ} \mathrm{C}$.

Cellular morphological examination. MA-10 cells were seeded at a concentration of $6 \times 10^{5}$ cells $/ \mathrm{ml}$ in a $6 \mathrm{~cm}$ petri dish with $2 \mathrm{ml}$ Waymouth culture medium, and treated without or with different concentrations of propofol $(300,350$ and $400 \mu \mathrm{M}$ ) for $3 \mathrm{~h}$ at $37^{\circ} \mathrm{C}$. Propofol was diluted with DMSO. Cell morphology was observed under Olympus CK40 light microscopy at x100 magnification and the images were recorded by Olympus DP20 digital camera (Olympus Corporation, Tokyo, Japan).

MTT viability assay. An MTT assay is a colorimetric assay to detect cell viability (30). MA-10 cells $\left(1.2 \times 10^{4}\right.$ cells/well) were seeded in 96-well plates. When cell density reached $70-80 \%$ confluence at $37^{\circ} \mathrm{C}$, cells were treated with different concentrations of propofol $(0,10,50,100,300,400,500$ and $600 \mu \mathrm{M}$ ) for 1, 3, 6, 12 and $24 \mathrm{~h}$. Subsequently, $0.5 \mathrm{mg} / \mathrm{ml}$ MTT was added in each well at different time points (1, 3, 6,12 and $24 \mathrm{~h}$ ) and incubated at $37^{\circ} \mathrm{C}$ for $4 \mathrm{~h}$. The medium was then discarded, and $50 \mu 1$ DMSO was added into each well for dissolving the crystals by shaking the plate with a shaker at $37^{\circ} \mathrm{C}$ for $20 \mathrm{~min}$ in the dark. Cell viability was then detected at $\lambda=570 \mathrm{~nm}$ using a VersaMax ELISA reader (Molecular Devices, LLC, Sunnyvale, CA, USA) for the MTT assay (31).

Cell cycle analysis assay. To further investigate if propofol induces MA-10 cell death through apoptosis, the DNA contents were examined by PI staining through a flow cytometric analysis assay. The $6 \times 10^{5} \mathrm{MA}-10$ cells were seeded in a $6 \mathrm{~cm}$ petri dish with $2 \mathrm{ml}$ Waymouth culture medium, and treated with different concentrations of propofol $(0,100,300$ and $400 \mu \mathrm{M})$ for 3, 6, 12 and $24 \mathrm{~h}$. Cells were then harvested through trypsin digestion and centrifugation $\left(400 \mathrm{x} g\right.$ at $25^{\circ} \mathrm{C}$ for $10 \mathrm{~min}$ ), and washed by isoton II (1:4,000 dilution) and fixed with $70 \%$ ethanol for $2 \mathrm{~h}$ at $-20^{\circ} \mathrm{C}$. Following fixation, MA-10 cells were washed with cold isoton II (1:4,000 dilution) and collected by centrifugation $\left(400 \mathrm{xg}\right.$ at $25^{\circ} \mathrm{C}$ for $10 \mathrm{~min}$ ). Cell suspensions were then mixed with $100 \mu \mathrm{g} / \mathrm{ml}$ RNase A and stained with $40 \mu \mathrm{g} / \mathrm{ml}$ PI solution for $30 \mathrm{~min}$ at $25^{\circ} \mathrm{C}$. The stained cells were further analyzed for PI detection at $\lambda=488 \mathrm{~nm}$ with the BD FACScan flow cytometer (Becton-Dickinson and Company, Franklin Lakes, NJ, USA). Cells in sub-G1 phase contained reduced DNA contents in cell cycle distribution, which is considered as DNA fragmentation, a consequence of cell apoptosis (32). The percentages of cells in sub-G1, S and G2/M phases were calculated and analyzed using FACStation v6.1x and Modfit LT v3.3 software (Becton-Dickinson and Company).
Annexin V and PI double staining assay. After MA-10 cells were harvested by trypsin, which was rinsed with $2 \mathrm{ml}$ Waymouth culture medium, cell suspensions were centrifuged (400 x g at $25^{\circ} \mathrm{C}$ for $10 \mathrm{~min}$ ). The pellets were then resuspended by cold isoton II (1:4,000 dilution) and centrifuged again $\left(400 \mathrm{x} \mathrm{g}\right.$ at $25^{\circ} \mathrm{C}$ for $\left.10 \mathrm{~min}\right)$. The pellets were mixed with $100 \mu \mathrm{l}$ staining solution for $15 \mathrm{~min}$ at $25^{\circ} \mathrm{C}$ according to manufacturer's protocols of the Annexin V-FITC/PI apoptosis detection kit. The stained cells were analyzed at $\lambda=488 \mathrm{~nm}$ excitation using $515 \mathrm{~nm}$ band pass filter for FITC detection and $>600 \mathrm{~nm}$ band pass filter for PI detection with the BD FACScan flow cytometer (Becton-Dickinson and Company). The double-negative cells (viable), Annexin V single positive cells (early apoptotic), PI single positive cells (necrotic) and double positive cells (late apoptotic) can be depicted in four quadrants (33). The percentage of cells in four quadrants were calculated using FACStation v6.1x software.

Protein extraction and western blot assay. Following propofol $(0,100,300$ and $400 \mu \mathrm{M})$ treatment for $3,6,12$ and $24 \mathrm{~h}$, the medium was removed and cells were washed 3 times with cold PBS. Attached cells were then lysed by $20 \mu 1$ lysis buffer (20 mM Tris pH 7.5, $150 \mathrm{mM} \mathrm{NaCl,} 1 \mathrm{mM}$ EDTA, $1 \mathrm{mM}$ EGTA, 1\% Triton X-100, $2.5 \mathrm{mM}$ sodium pyrophosphate and $1 \mathrm{mM}$ sodium orthovanadate) with proteinase inhibitor cocktail (Sigma-Aldrich; Merck KGaA; cat. no. P5655). The cell pellets were resuspended with $10 \mu 1$ lysis buffer and mixed with cell lysates, and it was centrifuged at $12,000 \mathrm{x} \mathrm{g}$ for $12 \mathrm{~min}$ at $4^{\circ} \mathrm{C}$. The supernatants were then collected and stored at $-80^{\circ} \mathrm{C}$. Cell lysate protein concentrations were determined with a Lowry assay (34).

For western blot assay, $30 \mu \mathrm{g}$ total protein were separated by $12 \%$ SDS-PAGE gel with standard running buffer (25 mM Tris, 0.1\% SDS and $192 \mathrm{mM}$ glycine; $\mathrm{pH}$ 8.3) at $25^{\circ} \mathrm{C}$, and electrophoretically transferred to a polyvinylidene difluoride membrane at $4^{\circ} \mathrm{C}$. After $1 \%$ milk at $25^{\circ} \mathrm{C}$ for $3 \mathrm{~h}$ blocking of the membranes, the membranes were incubated with primary antibodies overnight at $4^{\circ} \mathrm{C}$, the membrane was washed 3 times and then incubated with HRP-conjugated secondary antibodies at $25^{\circ} \mathrm{C}$ for $1 \mathrm{~h}$, which was detected with an enhanced chemiluminescence kit through UVP EC3 BioImaging Systems (UVP; LLC, Phoenix, AZ, USA).

Statistical analysis. All data are expressed as mean \pm standard error of the mean of three independent experiments. Statistical significance of differences between control and propofol treated groups were analyzed by one-way analysis of variance and then least significance difference comparison. Statistical analysis was performed by using GraphPad Prism 6 software (GraphPad Software, Inc., La Jolla, CA, USA). P<0.05 was considered to indicate a statistically significant difference.

\section{Results}

Propofol induces morphological changes in MA-10 cells. MA-10 cells were treated with different concentrations of propofol $(0,300,350$ and $400 \mu \mathrm{M}$; Fig. 1). The morphology of cells was observed with light microscopy. Without propofol treatment, MA-10 cells firmly attached with polygonal shapes (Fig. 1). Following treatment with $400 \mu \mathrm{M}$ propofol for 


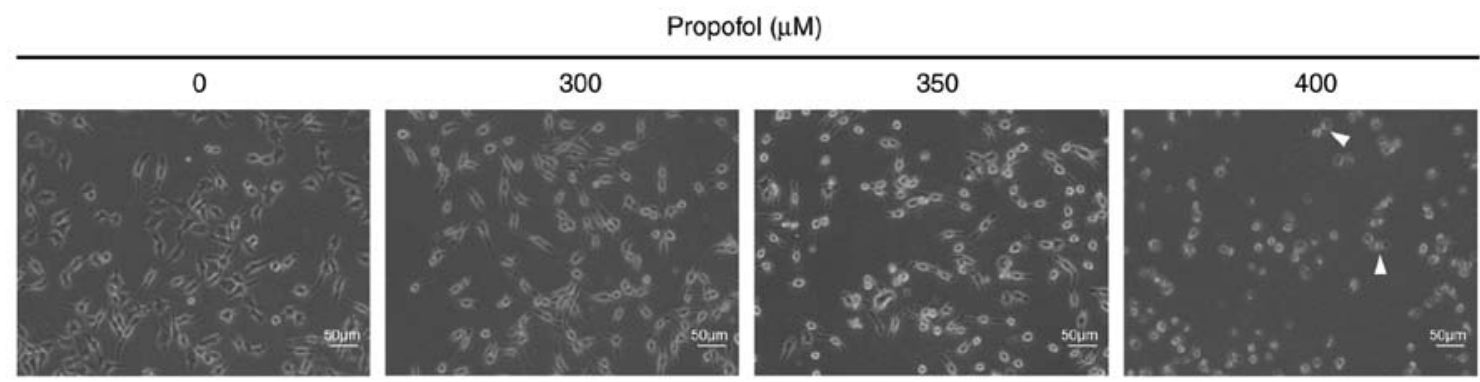

Figure 1. Propofol induces morphological changes in MA-10 cells. MA-10 cells were treated with different concentrations of propofol $(0,300,350$ and $400 \mu \mathrm{M})$ for $3 \mathrm{~h}$, and then the morphological changes were observed under light microscopy (scale bar, $50 \mu \mathrm{m}$; arrow, cell membrane blebbing).

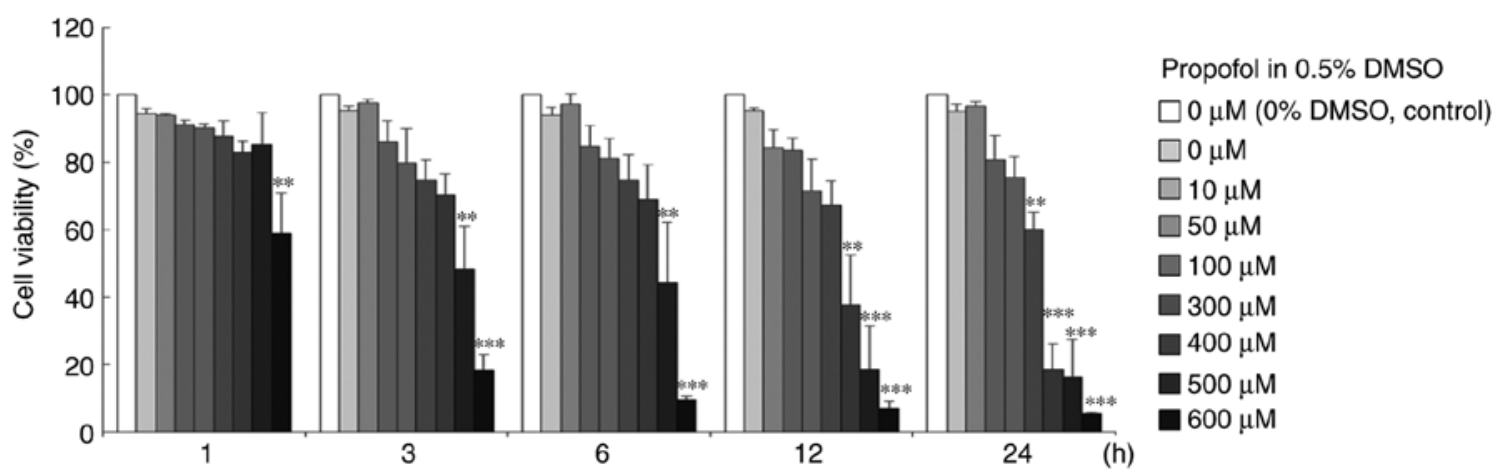

Figure 2. Propofol decreases MA-10 cell viability with time- and dose-dependent associations. MA-10 cells were treated with 0, 10, 50, 100, 300, 400,500 and $600 \mu \mathrm{M}$ propofol for 1,3,6,12 and $24 \mathrm{~h}$. Cell viabilities were examined with an MTT viability assay. Results are depicted as the percentages of cell growth relative to control groups. ${ }^{* *} \mathrm{P}<0.01$ and ${ }^{* * *} \mathrm{P}<0.005$, compared with control. DMSO, dimethyl sulfoxide.

$3 \mathrm{~h}$ (Fig. 1), cells transformed to round shape and possessed apparent blebbing in the plasma membrane. These results demonstrated that propofol causes membrane blebbing in MA-10 cells, indicating that propofol may induce cell death through apoptosis in MA-10 mouse Leydig tumor cells.

Propofol decreases MA-10 cell viability with time-and dose-dependent associations. For investigating the effect of propofol upon MA-10 cell viability, an MTT viability test was conducted on MA-10 cells with $0,10,50,100,300$, 400,500 and $600 \mu \mathrm{M}$ propofol for 1, 3, 6, 12 and $24 \mathrm{~h}$ treatments (Fig. 2). The results demonstrated that cell viability was significantly reduced by propofol from $300-600 \mu \mathrm{M}$ for $24 \mathrm{~h}$ ( $\mathrm{P}<0.05$; Fig. 2). The results indicated that propofol induces cell death in MA-10 cells.

Propofol regulates the cell cycle in MA-10 cells. To investigate whether propofol could influence the cell cycle and result in apoptosis, MA-10 cells were treated with propofol, and their DNA contents were determined with flow cytometry. Different dosages of propofol were used to treat cells examining the impacts on cell cycle progression. The results demonstrated that increased sub-G1 phase cells were significantly increased at $400 \mu \mathrm{M}$ propofol for $3-24 \mathrm{~h}$ in MA-10 cells $(\mathrm{P}<0.05$; Fig. 3A). Additionally, the significant increases of $\mathrm{G} 2 / \mathrm{M}$ phase cells were observed at $300 \mu \mathrm{M}$ propofol at 6 and $12 \mathrm{~h}$ in MA-10 cells $(\mathrm{P}<0.05$; Fig. 3B). These results demonstrated that propofol regulated the cell cycle to increase sub-G1 phase cells and then induced apoptosis in MA-10 cells. Furthermore, propofol reduced the cell population of MA-10 cells in the G2/M phase.
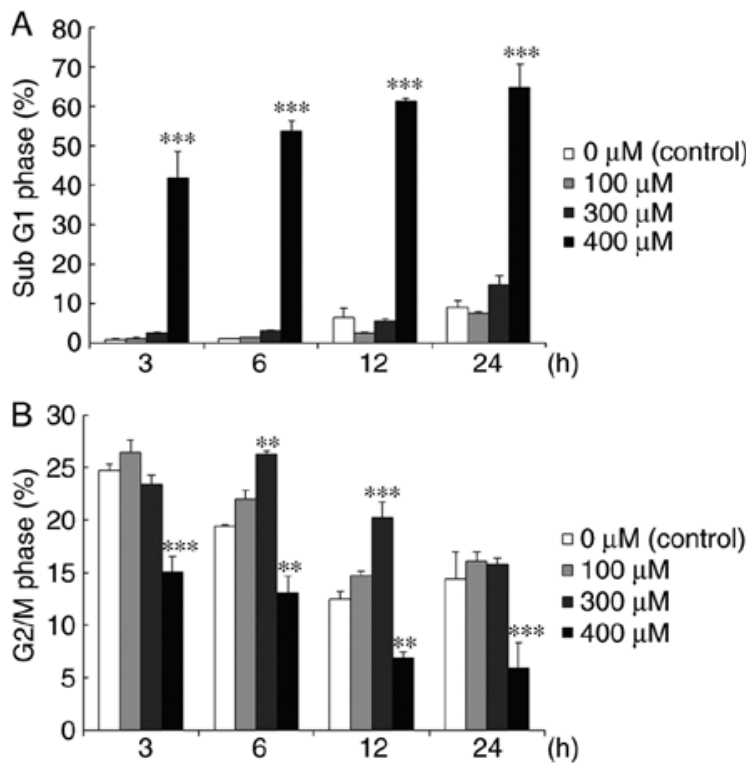

Figure 3. Propofol induces cell apoptosis upon MA-10 cells. MA-10 cells were treated with $0,100,300$ and $400 \mu \mathrm{M}$ propofol for 3, 6, 12 and $24 \mathrm{~h}$. Cell were fixed and stained with propidium iodide, and (A) sub-G1 phase and (B) G2/M phase cells in MA-10 cells were then analyzed and depicted. Sub-G1 phase indicates cells containing reduced DNA content, compared with normal control cells, demonstrating apoptosis. ${ }^{* *} \mathrm{P}<0.01$ and ${ }^{* * *} \mathrm{P}<0.005$, compared with control.

Propofol induces cell apoptosis in MA-10 cells. It was observed that propofol stimulated cell death, causing DNA fragmentation and membrane blebbing. To confirm that propofol could 
A

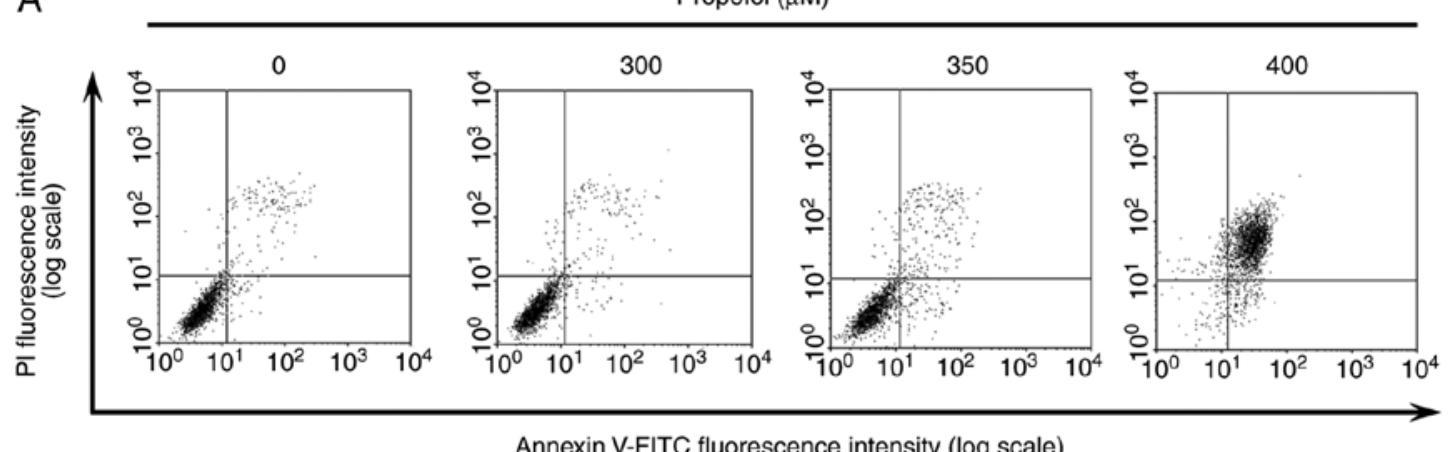

Annexin V-FITC fluorescence intensity (log scale)
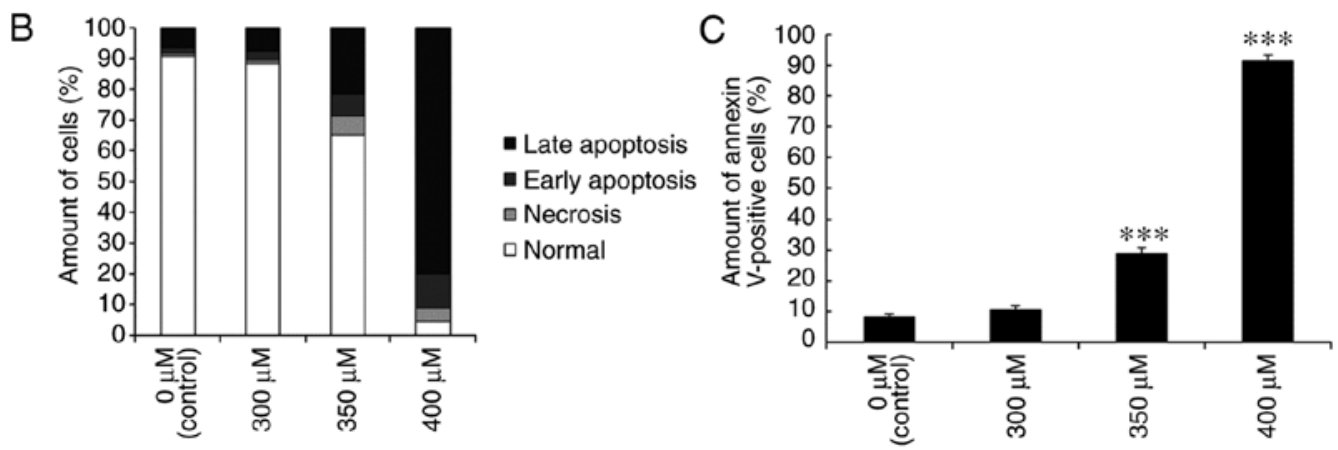

Figure 4. Propofol induces cell apoptosis in MA-10 cells. MA-10 cells were treated with 0, 300, 350 and $400 \mu$ M propofol for 3 h. (A) The apoptotic status of propofol-treated cells was detected by Annexin V and PI double staining assay. The double-negative cells (viable cells), Annexin V single positive cells (early apoptotic cells), PI single positive cells (necrotic cells) and Annexin V and PI double positive cells (late apoptotic cells) were depicted. (B) The various percentages of late apoptotic cells, early apoptotic cells, necrotic cells, and normal cells in each treatment. (C) The difference of Annexin V positive cells (early apoptotic and late apoptotic status) was then analyzed with propofol treatment. ${ }^{* * *} \mathrm{P}<0.005$, compared with control. PI, propidium iodide; FITC, fluorescein isothiocyanate.

induce MA-10 cell apoptosis, the Annexin V and PI double staining method followed by flow cytometry were conducted. It is well known that percentages of double-negative cells (viable), Annexin V single positive cells (early apoptotic), PI single positive cells (necrotic) and double positive cells (late apoptotic) are observed in four quadrants by double staining, to demonstrate the cell apoptotic phenomenon (35). The results demonstrated that the number of Annexin V-positive cells was significantly increased by propofol at 350 and $400 \mu \mathrm{M}$ for $3 \mathrm{~h}$ in MA-10 cells $(\mathrm{P}<0.05$; Fig. 4). These results indicated that propofol induces apoptosis in MA-10 cells.

Propofol activates the caspase cascade to induce apoptosis in MA-10 cells. The caspase cascade is an essential inducer of apoptosis, which is involved with extrinsic and intrinsic pathways (17-19,36). According to previous experiments, propofol promotes apoptosis in MA-10 cells (Figs. 3 and 4); therefore whether propofol induced apoptosis through apoptotic extrinsic and intrinsic pathways, inducing cleavages of caspase-8, -9 and -3 , and PARP, was investigated. The present data demonstrated that propofol at $400 \mu \mathrm{M}$ for $3 \mathrm{~h}$ significantly induces cleaved caspase-8, -9 and -3, and PARP expression levels in MA-10 cells ( $\mathrm{P}<0.05$; Fig. 5A-E). Furthermore, $350 \mu \mathrm{M}$ propofol for $6 \mathrm{~h}$ also significantly induced cleaved caspase-8 and -3 , and PARP expression levels in MA-10 cells ( $\mathrm{P}<0.05$; Fig. 5A, B, D and E).

Propofol activates MAPK pathways to induce apoptosis in MA-10 cells. Previous studies demonstrated that MAPK pathways regulate cell proliferation, apoptosis and growth $(21,32)$. Therefore, whether propofol-induced MA-10 cell apoptosis is modulated by MAPK pathways was examined by determining the expression levels of MAPK proteins with a western blot assay. The data demonstrated that propofol at $400 \mu \mathrm{M}$ for $3 \mathrm{~h}$ significantly induced the expression levels of phospho-JNK, phospho-ERK and phospho-p38 ( $\mathrm{P}<0.05$; Fig. 6A-D), and the expression of phospho-p38 was prolonged to $6 \mathrm{~h}$ by $400 \mu \mathrm{M}$ propofol in MA-10 cells $(\mathrm{P}<0.05$; Fig. $6 \mathrm{~A}$ and $\mathrm{D})$. Dosage at $350 \mu \mathrm{M}$ of propofol for 3 and $6 \mathrm{~h}$ significantly induced the expression levels of phospho-JNK and phospho-ERK ( $\mathrm{P}<0.05$; Fig. 6A-C). Notably, a reduced dosage of propofol at $300 \mu \mathrm{M}$ for $3 \mathrm{~h}$ also significantly induced the expression of phospho-ERK in MA-10 cells $(\mathrm{P}<0.05$; Fig. 6A and $\mathrm{C}$ ). These results demonstrated that propofol at different dosages and temporal durations significantly induce MAPK signal pathways, implying that propofol may activate MAPK pathways to induce apoptosis in MA-10 cells.

In fact, the stimulation of MAPKs, caspases and the cleavage of PARP occurred at $3 \mathrm{~h}$ of propofol treatment in MA-10 $(400 \mu \mathrm{M})$ cells, indicating that propofol could induce the caspase cascade and MAPK pathways within a similar time frame.

Propofol suppresses the Akt pathway to induce apoptosis in MA-10 cells. Studies demonstrated that Akt pathway is a pro-survival pathway, which can inhibit apoptotic signal cascades and activate pro-survival signal cascades $(24,25)$. To further determine whether propofol would induce apoptosis in MA-10 cells through inhibiting the Akt pathway, the expression levels of Akt, phospho-Akt, mTOR and phospho-mTOR 
A
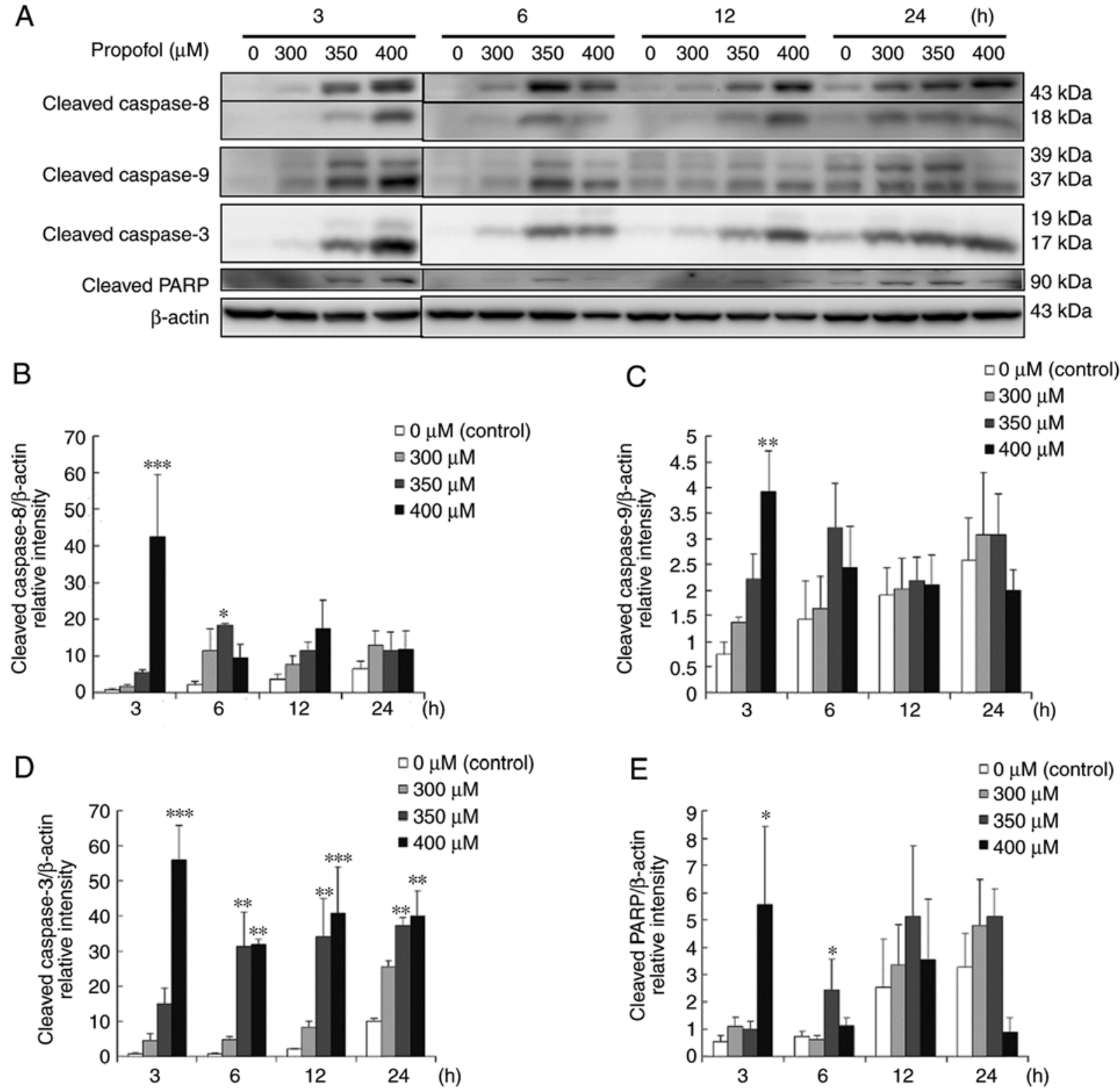

Figure 5. Propofol activates the caspase cascade to induce apoptosis in MA-10 cells. MA-10 cells were treated with different concentrations of propofol ( 0,300 , 350 and $400 \mu \mathrm{M})$ for 3, 6, 12 and $24 \mathrm{~h}$. (A) A western blot assay was used to determine cleaved caspase-8 (43/18 kDa), $-9(39 / 37 \mathrm{kDa})$ and $-3(17 / 19 \mathrm{kDa})$, and PARP (85-90 kDa). Integrated optical densities of (B) cleaved caspase-8, (C) -9 and (D) -3, and (E) PARP proteins were normalized by $\beta$-actin (43 kDa) in each lane. ${ }^{*} \mathrm{P}<0.05,{ }^{* *} \mathrm{P}<0.01$ and ${ }^{* * * *} \mathrm{P}<0.005$, compared with control. PARP, poly(ADP-ribose) polymerase.

were investigated with a western blot assay. The results demonstrated that $400 \mu \mathrm{M}$ propofol for 3-12 h significantly reduced the expression levels of phospho-Akt and phospho-mTOR, but not at $6 \mathrm{~h}$ for phospho-mTOR, in MA-10 cells $(\mathrm{P}<0.05$; Fig. 7A-C). A reduced concentration of propofol $(350 \mu \mathrm{M})$ downregulated the expression levels of phospho-Akt at $12 \mathrm{~h}$, and $300 \mu \mathrm{M}$ reduced the expression of phospho-mTOR at $3 \mathrm{~h}$ $(\mathrm{P}<0.05$; Fig. 7A-C). These results demonstrated that propofol at different dosages and temporal durations significantly inhibits the Akt pathway, implying that propofol decreases the Akt pathway to induce apoptosis in MA-10 cells.

\section{Discussion}

Numerous studies regarding sedative drug effects have focused on the clinical dosages and their side effects $(37,38)$, and a number of researches demonstrated that propofol induces neurotoxicity $(38,39)$. A previous study indicated that sedative drugs, including propofol, induce apoptosis in various cancer cells (8). Additionally, it has been demonstrated that propofol has anticancer ability on numerous cancer types, including pancreatic (5), lung (6) and epithelial ovarian cancer (8). Nevertheless, whether propofol could serve as anticancer drug for Leydig tumor cases and the involved mechanisms are not clear. Therefore, whether propofol induces apoptosis in MA-10 cells and the mechanism was investigated in the present study.

Intense transformations in cellular architecture are essential characterizations in apoptosis, and the activation of caspases regulates the weakening of the cell cytoskeleton, triggering morphological changes, including membrane blebbing and cell shrinkage (40). The present results demonstrated that propofol induces membrane blebbing and cell shrinkage, indicating 
A

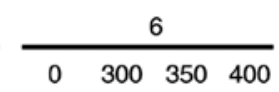

$\frac{12}{0 \quad 300 \quad 350 \quad 400}$

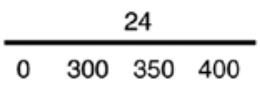

(h)

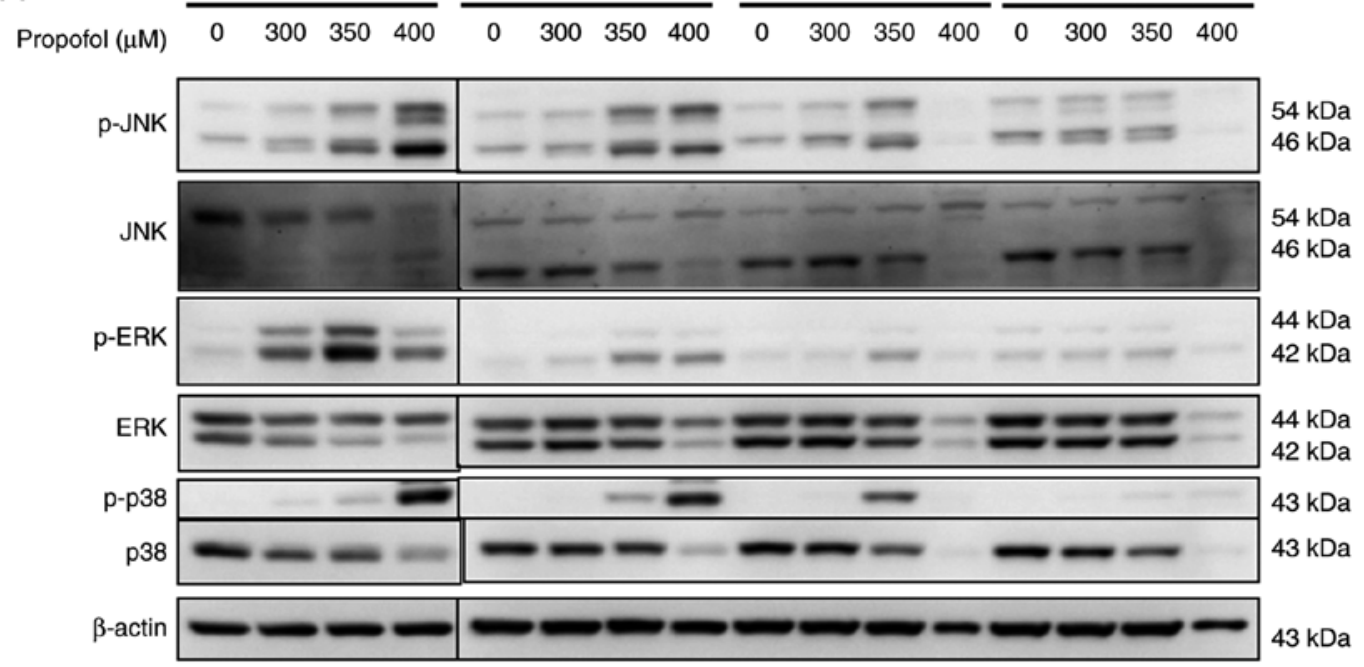

B
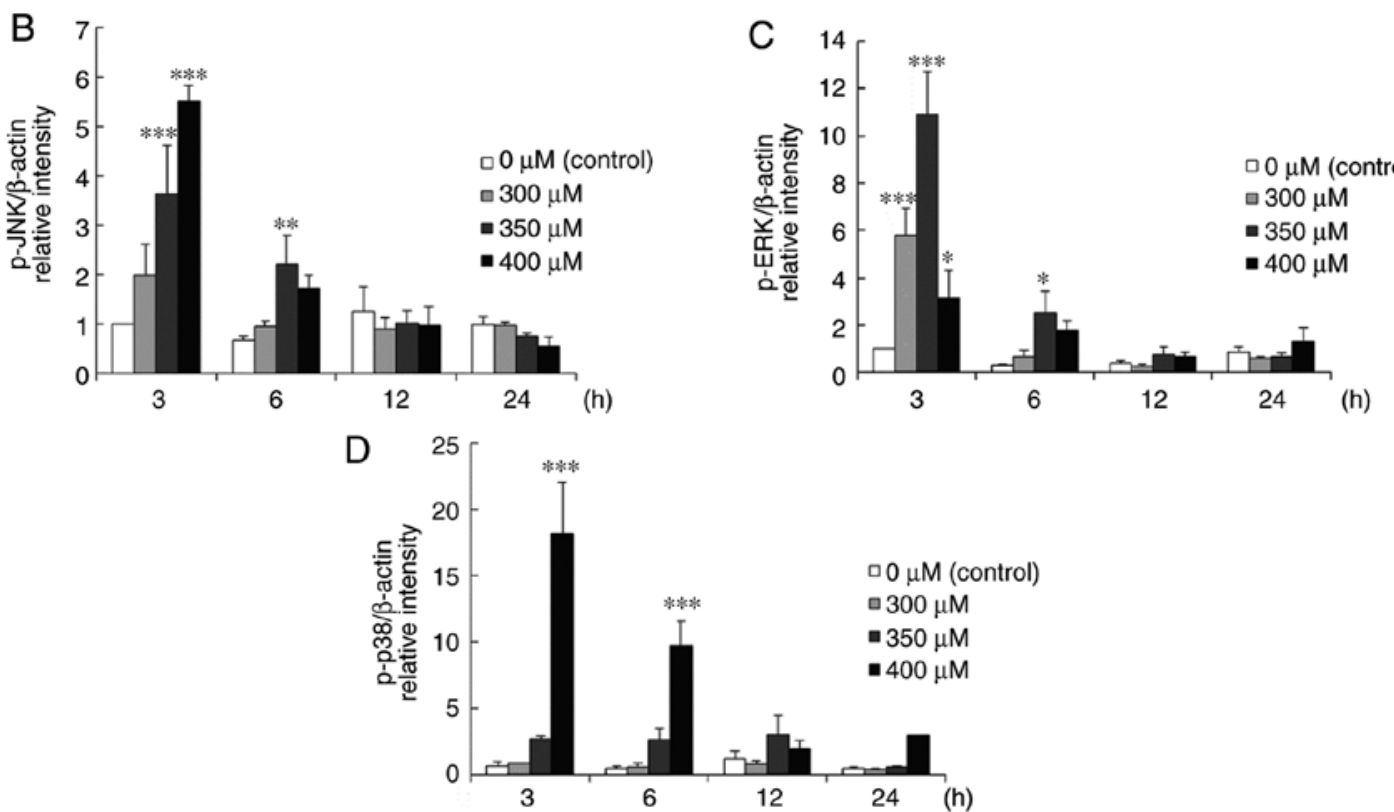

Figure 6. Propofol activates MAPK pathways to induce apoptosis in MA-10 cells. MA-10 cells were treated with different concentrations of propofol (0, 300, 350 and $400 \mu \mathrm{M})$ for 3, 6, 12 and $24 \mathrm{~h}$. (A) p-JNK (54/46 kDa), JNK, p-ERK (44/42 kDa), ERK, p-p38 (43 kDa) and p38 were detected by western blot analysis. The integrated optical densities of (B) p-JNK, (C) p-ERK and (D) phospho-p38 proteins were normalized by $\beta$-actin (43 kDa) in each lane. ${ }^{*} \mathrm{P}<0.05$, ${ }^{* *} \mathrm{P}<0.01$ and ${ }^{* * *} \mathrm{P}<0.005$, compared with control. ERK, extracellular signal-regulated kinase; JNK, c-Jun N-terminal kinase; p-, phospho-.

that propofol influences the cytoskeleton and morphological changes to induce apoptosis in MA-10 cells. In the present study, the effects of propofol in MA-10 cell viability were investigated.

Propofol significantly increased MA-10 cell in the sub-G1 phase, indicating that propofol causes DNA fragmentation and induces MA-10 cell apoptosis. Notably, propofol did not induce increased MA-10 cells in the G2/M phase. Previous studies demonstrated that sub-G1 phase increase and/or G2/M phase arrest could induce cell death through apoptosis $(41,42)$. Therefore, the present results advocated that propofol-induced apoptosis is associated with cell cycle regulation, and the detailed mechanisms require further investigation. Additionally, the Annexin V and PI double staining assay also demonstrated that propofol induces MA-10 cell apoptosis in a dose-dependent manner, indicating that propofol induces cell apoptosis.
Apoptosis is primarily started by extrinsic and intrinsic signals to activate caspase cascades (17). The present data demonstrated that propofol activates extrinsic and intrinsic pathways to induce MA-10 cell apoptosis. Previous studies reported that propofol has the same effects in murine hepatocellular carcinoma $(9,43)$. Thus, the present observations are in line with other studies.

Apoptotic pathways are controlled by numerous pathways, and the MAPK pathways, including JNK, ERK1/2 and p38 MAPK, may respond to cellular stress regulating cell survival and/or apoptosis (21). Studies demonstrated that JNKs can be stimulated by numerous different stimuli, including stress factors, growth factors and cytokines $(44,45)$. Additionally, studies indicated that the JNK pathway results in a switch from apoptosis to autophagy to survival in choriocarcinoma cells (46), and inhibit apoptosis in acute myeloid leukemia cells (47). However, it was reported that JNK triggers apoptosis by activating c-Jun and mitochondria 
A
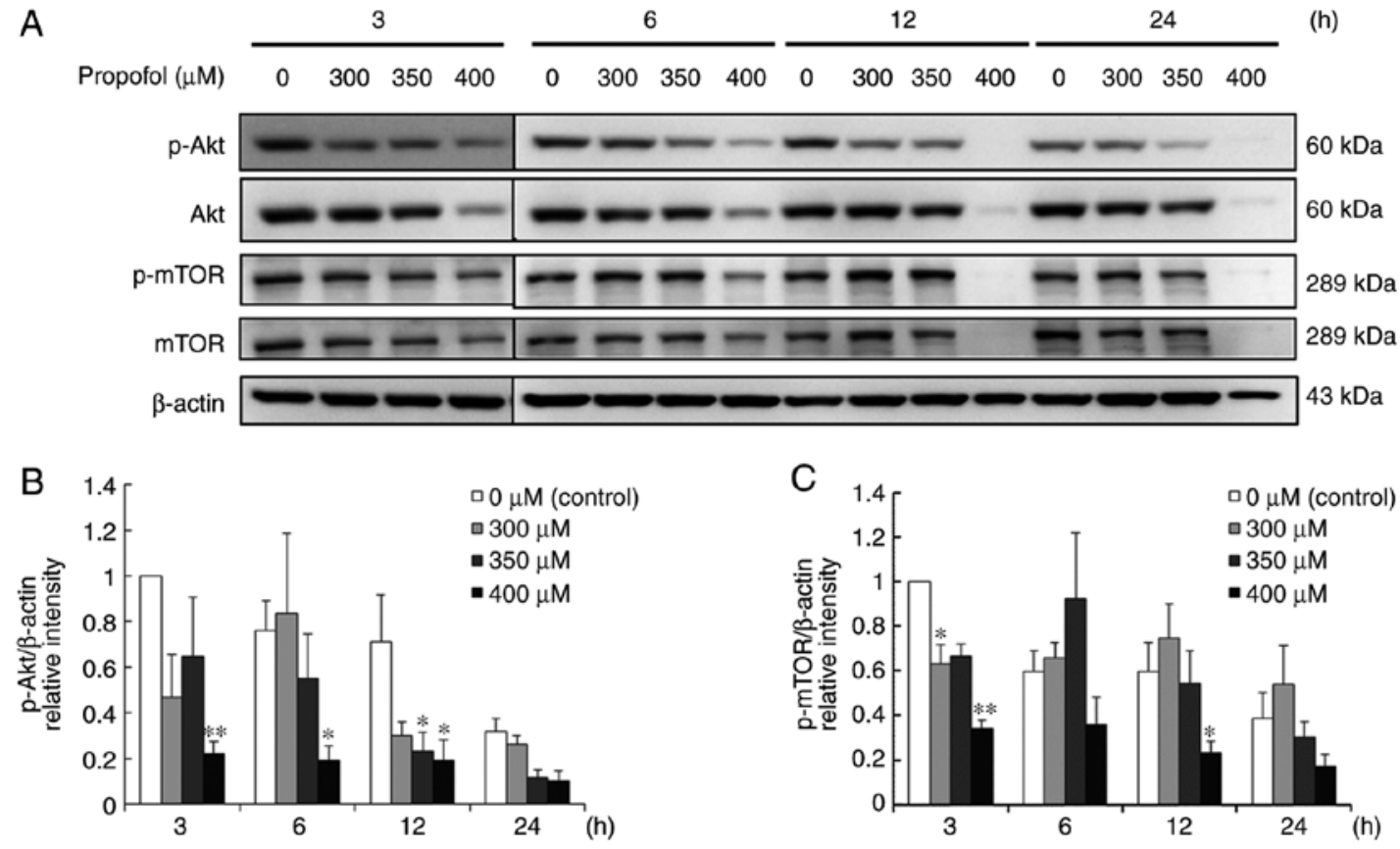

Figure 7. Propofol suppresses the Akt pathway to induce apoptosis in MA-10 cells. MA-10 cells were treated with different concentrations of propofol (0, 300 , 350 and $400 \mu \mathrm{M})$ for 3, 6, 12 and $24 \mathrm{~h}$. (A) p-Akt (60 kDa), Akt, p-mTOR (289 kDa) and mTOR were detected by western blot analysis. The integrated optical densities of (B) p-Akt and (C) p-mTOR proteins were normalized with $\beta$-actin (43 kDa) in each lane. ${ }^{*} \mathrm{P}<0.05$ and ${ }^{* *} \mathrm{P}<0.01$, compared with control. mTOR, mechanistic target of rapamycin kinase; p-, phospho-.

apoptotic pathways, which are induced by irradiation, DNA damage and oxidative stress (48). Studies demonstrated that ERK may induce apoptosis by mediating cell cycle arrest due to DNA damage (49). Similar to the JNK pathway, the role of p38 in apoptosis is diverse, which could inhibit caspase-3 activity in neuronal cells (50), which may enhance the expression of TNF- $\alpha$, and then result in cell apoptosis (51). Numerous studies reported that propofol inhibits MAPK pathways in different cells to inhibit migration $(9,52)$ or inflammation $(53,54)$. In the present data, propofol increased the expression levels of phospho-JNK, phospho-ERK and phospho-p38 in MA-10 mouse Leydig tumor cells, indicating that propofol induces MAPK pathways and as a result apoptosis in MA-10 cells. Notably, propofol reduced the total protein expression levels of JNK, ERK and p38, indicating that propofol may rapidly stimulate phosphorylation of MAPKs and result in MAPK instability, and then result in MAPK degradation.

It has been demonstrated that Akt signaling is a pro-survival pathway, which can inhibit apoptotic signal cascades and activate pro-survival signals (24). It is known that activation of the phosphoinositide 3-kinase/Akt pathway is observed in the formation of a number of cancer types, including breast, endometrial and gastric cancer (55-57). In fact, the role of propofol in the Akt pathway is diverse, which may inhibit Akt activity in macrophages to induce cell apoptosis (58), while propofol may also keep rat cardiomyocytes alive whilst avoiding doxorubicin-induced toxicity through activation of the Akt pathway (59). The present data demonstrated that propofol decreases the expression levels of phospho-Akt and phospho-mTOR in MA-10 cells. Thus, propofol attenuates Akt activity to induce apoptosis in MA-10 cells.

A previous study demonstrated that patients treated with propofol would receive total doses ranging between $90-600 \mathrm{mg}$ with an initial bolus dose, depending on patient age and body weight, followed by intermittent intravenous bolus infusion to maintain the appropriate level of sedation (60). The dosages of propofol ranging from $90-600 \mathrm{mg}$ are approximately equal to $500-3,000 \mu \mathrm{M}$. In the present study, propofol doses ranging from 300-400 $\mu \mathrm{M}$ had a significant inhibitory effect on cell viability and induced apoptosis in MA-10 cells, implying that a low dosage of propofol would have an effective potency to exterminate tumor cells.

In conclusion, propofol induces cell apoptosis through the stimulation of caspase and MAPK pathways, and the inhibition of the Akt pathway in MA-10 mouse Leydig tumor cells.

\section{Acknowledgements}

Not applicable.

\section{Funding}

This work was supported by Chi Mei-NCKU hospital grant CMNCKU10705 (FCK and BMH) and Ministry of Science and Technology MOST 105-2320-B-006-028 (BMH), Taiwan, Republic of China.

\section{Availability of data and materials}

The datasets used and/or analyzed during the current study are available from the corresponding author on reasonable request.

\section{Authors' contributions}

FCK and SCW contributed to conducting the experiments and statistical analysis. ECS and MMC designed the experiment 
and wrote the manuscript. KLW and KSC contributed to statistical analysis and the writing of the manuscript. YCC and $\mathrm{BMH}$ contributed to experimental designs, data interpretation, writing of the manuscript, and ensuring the accuracy and the integrity of whole work. All authors read and approved the final version of the manuscript.

\section{Ethics approval and consent to participate}

Not applicable.

\section{Patient consent for publication}

Not applicable.

\section{Competing interests}

The authors declare that they have no competing interests.

\section{References}

1. Busettini $\mathrm{C}$ and Frolich MA: Effects of mild to moderate sedation on saccadic eye movements. Behav Brain Res 272: 286-302, 2014.

2. Cassinello F, Prieto I, Del Olmo M, Rivas S and Strichartz GR: Cancer surgery: How may anesthesia influence outcome? J Clin Anesth 27: 262-272, 2015.

3. Wang P, Chen J, Mu LH, Du QH, Niu XH and Zhang MY: Propofol inhibits invasion and enhances paclitaxel- induced apoptosis in ovarian cancer cells through the suppression of the transcription factor slug. Eur Rev Med Pharmacol Sci 17: 1722-1729, 2013.

4. Ye Z, Jingzhong L, Yangbo L, Lei C and Jiandong Y: Propofol inhibits proliferation and invasion of osteosarcoma cells by regulation of microRNA-143 expression. Oncol Res 21: 201-207, 2013.

5. Du QH, Xu YB, Zhang MY, Yun P and He CY: Propofol induces apoptosis and increases gemcitabine sensitivity in pancreatic cancer cells in vitro by inhibition of nuclear factor-kappaB activity. World J Gastroenterol 19: 5485-5492, 2013.

6. Cui WY, Liu Y, Zhu YQ, Song T and Wang QS: Propofol induces endoplasmic reticulum (ER) stress and apoptosis in lung cancer cell H460. Tumour Biol 35: 5213-5217, 2014.

7. Xing SG, Zhang KJ, Qu JH, Ren YD and Luan Q: Propofol induces apoptosis of non-small cell lung cancer cells via ERK1/2-dependent upregulation of PUMA. Eur Rev Med Pharmacol Sci 22: 4341-4349, 2018.

8. Su Z, Hou XK and Wen QP: Propofol induces apoptosis of epithelial ovarian cancer cells by upregulation of microRNA let-7i expression. Eur J Gynaecol Oncol 35: 688-691, 2014.

9. Liu SQ, Zhang JL, Li ZW, Hu ZH, Liu Z and Li Y: Propofol inhibits proliferation, migration, invasion and promotes apoptosis through down-regulating miR-374a in hepatocarcinoma cell lines. Cell Physiol Biochem 49: 2099-2110, 2018.

10. Yu FX and Guan KL: The Hippo pathway: Regulators and regulations. Genes Dev 27: 355-371, 2013.

11. Hanahan D and Weinberg RA: The hallmarks of cancer. Cell 100 57-70, 2000.

12. Kuwabara M, Asanuma T, Niwa K and Inanami O: Regulation of cell survival and death signals induced by oxidative stress. J Clin Biochem Nutr 43: 51-57, 2008.

13. Kroemer G, Galluzzi L, Vandenabeele P, Abrams J, Alnemri ES, Baehrecke EH, Blagosklonny MV, El-Deiry WS, Golstein P, Green DR, et al: Classification of cell death: Recommendations of the nomenclature committee on cell death 2009. Cell Death Differ 16: 3-11, 2009.

14. Ouyang L, Shi Z, Zhao S, Wang FT, Zhou TT, Liu B and Bao JK: Programmed cell death pathways in cancer: A review of apoptosis, autophagy and programmed necrosis. Cell Prolif 45: 487-498, 2012.

15. Long JS and Ryan KM: New frontiers in promoting tumour cell death: Targeting apoptosis, necroptosis and autophagy. Oncogene 31: 5045-5060, 2012.
16. Kerr JF, Wyllie AH and Currie AR: Apoptosis: A basic biological phenomenon with wide-ranging implications in tissue kinetics. Br J Cancer 26: 239-257, 1972.

17. Oliveira JB and Gupta S: Disorders of apoptosis: Mechanisms for autoimmunity in primary immunodeficiency diseases. J Clin Immunol 28 (Suppl 1): S20-S28, 2008.

18. Lewis-Wambi JS and Jordan VC: Estrogen regulation of apoptosis: How can one hormone stimulate and inhibit? Breast Cancer Res 11: 206, 2009.

19. Cossarizza A, Baccarani-Contri M, Kalashnikova G and Franceschi C: A new method for the cytofluorimetric analysis of mitochondrial membrane potential using the J-aggregate forming lipophilic cation 5,5',6,6'-tetrachloro-1,1',3,3'-tetraethylbenzimidazolcarbocyanine iodide (JC-1). Biochemical and biophysical research communications Biochem Biophys Res Commun 197: 40-45, 1993.

20. Green DR and Reed JC: Mitochondria and apoptosis. Science 281: 1309-1312, 1998

21. Johnson GL and Lapadat R: Mitogen-activated protein kinase pathways mediated by ERK, JNK, and p38 protein kinases. Science 298: 1911-1912, 2002.

22. Son Y, Cheong YK, Kim NH, Chung HT, Kang DG and Pae HO: Mitogen-activated protein kinases and reactive oxygen species: How can ROS activate MAPK pathways? J Signal Transduct 2011: 792639, 2011.

23. Rauch N, Rukhlenko OS, Kolch W and Kholodenko BN: MAPK kinase signalling dynamics regulate cell fate decisions and drug resistance. Curr Opin Struct Biol 41: 151-158, 2016.

24. Markman B, Dienstmann R and Tabernero J: Targeting the PI3K/Akt/mTOR pathway-beyond rapalogs. Oncotarget 1: 530-543, 2010.

25. Hein AL, Ouellette MM and Yan Y: Radiation-induced signaling pathways that promote cancer cell survival (review). Int J Oncol 45: 1813-1819, 2014.

26. Zhou C, Zhao XM, Li XF, Wang C, Zhang XT, Liu XZ, Ding XF, Xiang SL and Zhang J: Curcumin inhibits AP- $2 \gamma$-induced apoptosis in the human malignant testicular germ cells in vitro. Acta Pharmacol Sin 34: 1192-1200, 2013.

27. Pang S, Zhang L, Shi Y and Liu Y: Unclassified mixed germ cell-sex cord-stromal tumor with multiple malignant cellular elements in a young woman: A case report and review of the literature. Int J Clin Exp Pathol 7: 5259-5266, 2014.

28. Olivier P, Simoneau-Roy J, Francoeur D, Sartelet H, Parma J, Vassart G and Van Vliet G: Leydig cell tumors in children: Contrasting clinical, hormonal, anatomical, and molecular characteristics in boys and girls. J Pediatr 161: 1147-1152, 2012.

29. Gheorghisan-Galateanu AA: Leydig cell tumors of the testis: A case report. BMC Res Notes 7: 656, 2014

30. Green LM, Reade JL and Ware CF: Rapid colorimetric assay for cell viability: Application to the quantitation of cytotoxic and growth inhibitory lymphokines. J Immunol Methods 70: 257-268, 1984

31. So EC, Chen YC, Wang SC, Wu CC, Huang MC, Lai MS Pan BS, Kang FC and Huang BM: Midazolam regulated caspase pathway, endoplasmic reticulum stress, autophagy, and cell cycle to induce apoptosis in MA-10 mouse Leydig tumor cells. Onco Targets Ther 9: 2519-2533, 2017.

32. Chang MM, Lai MS, Hong SY, Pan BS, Huang H, Yang SH, Wu CC, Sunny Sun H, Chuang JI, Wang CY and Huang BM: FGF9/FGFR2 increase cell proliferation by activating ERK1/2, $\mathrm{Rb} / \mathrm{E} 2 \mathrm{~F} 1$ and cell cycle pathways in mouse Leydig tumor cells. Cancer Sci 109: 3503-3518, 2018.

33. Kang FC, Wang SC, Chang MM, Pan BS, Wong KL, Cheng KS, So EC and Huang BM: Midazolam activates caspase, MAPKs and endoplasmic reticulum stress pathways, and inhibits cell cycle and Akt pathway, to induce apoptosis in TM3 mouse Leydig progenitor cells. Onco Targets Ther 11: 1475-1490, 2018.

34. Lowry OH, Rosebrough NJ, Farr AL and Randall RJ: Protein measurement with the Folin phenol reagent. J Biol Chem 193: 265-275, 1951.

35. vanEngeland $M$, Ramaekers FC, Schutte $B$ and Reutelingsperger $C P$ : A novel assay to measure loss of plasma membrane asymmetry during apoptosis of adherent cells in culture. Cytometry 24: 131-139, 1996.

36. Creagh EM and Martin SJ: Caspases: Cellular demolition experts. Biochem Soc Trans 29: 696-702, 2001.

37. Harris CE, Grounds RM, Murray AM, Lumley J, Royston D and Morgan M: Propofol for long-term sedation in the intensive care unit. A comparison with papaveretum and midazolam. Anaesthesia 45: 366-372, 1990. 
38. Radke J: Analgesia and sedation in intensive care patients. Der Anaesthesist (German) 41: 793-808, 1992.

39. Yu D, Jiang Y, Gao J, Liu B and Chen P: Repeated exposure to propofol potentiates neuroapoptosis and long-term behavioral deficits in neonatal rats. Neurosci Lett 534: 41-46, 2013.

40. Taylor RC, Cullen SP and Martin SJ: Apoptosis: Controlled demolition at the cellular level. Nat Rev Mol Cell Biol 9: 231-241, 2008.

41. Paul-Samojedny M, Suchanek R, Borkowska P, Pudelko A, Owczarek A, Kowalczyk M, Machnik G, Fila-Danilow A and Kowalski J: Knockdown of AKT3 (PKBgamma) and PI3KCA suppresses cell viability and proliferation and induces the apoptosis of glioblastoma multiforme T98G cells. Biomed Res Int 2014: 768181, 2014.

42. Zhang C, Chen Z, Zhou X, Xu W, Wang G, Tang X, Luo L, Tu J Zhu Y, Hu W, et al: Cantharidin induces G/M phase arrest and apoptosis in human gastric cancer SGC-7901 and BGC-823 cells Oncol Lett 8: 2721-2726, 2014.

43. Khan AA, Jabeen M, Khan AA and Owais M: Anticancer efficacy of a novel propofol-linoleic acid-loaded escheriosomal formulation against murine hepatocellular carcinoma. Nanomedicine (London) 8: 1281-1294, 2013.

44. Hibi M, Lin A, Smeal T, Minden A and Karin M: Identification of an oncoprotein- and UV-responsive protein kinase that binds and potentiates the c-Jun activation domain. Genes Dev 7: 2135-2148, 1993.

45. Cano E, Hazzalin CA and Mahadevan LC: Anisomycin-activated protein kinases $\mathrm{p} 45$ and p55 but not mitogen-activated protein kinases ERK-1 and -2 are implicated in the induction of c-fos and c-jun. Mol Cell Biol 14: 7352-7362, 1994.

46. Shen Y, Yang J, Zhao J, Xiao C, Xu C and Xiang Y: The switch from ER stress-induced apoptosis to autophagy via ROS-mediated JNK/p62 signals: A survival mechanism in methotrexate-resistant choriocarcinoma cells. Exp Cell Res 334 207-218, 2015

47. Lin X, Fang Q, Chen S, Zhe N, Chai Q, Yu M, Zhang Y, Wang Z and Wang J: Heme oxygenase-1 suppresses the apoptosis of acute myeloid leukemia cells via the JNK/c-JUN signaling pathway. Leuk Res 39: 544-552, 2015.

48. Dhanasekaran DN and Reddy EP: JNK signaling in apoptosis. Oncogene 27: 6245-6251, 2008.

49. Tang D, Wu D, Hirao A, Lahti JM, Liu L, Mazza B, Kidd VJ, Mak TW and Ingram AJ: ERK activation mediates cell cycle arrest and apoptosis after DNA damage independently of p53. J Biol Chem 277: 12710-12717, 2002.

50. Lee JM,Lee JM,Kim KR, Im H and Kim YH: Zinc preconditioning protects against neuronal apoptosis through the mitogen-activated protein kinase-mediated induction of heat shock protein 70 Biochem Biophys Res Commun 459: 220-226, 2015.
51. Zhang B, Wu T, Wang Z, Zhang Y, Wang J, Yang B, Zhao Y, Rao Z and Gao J: p38MAPK activation mediates tumor necrosis factor-alpha-induced apoptosis in glioma cells. Mol Med Rep 11: 3101-3107, 2015

52. Wu KC, Yang ST, Hsia TC, Yang JS, Chiou SM, Lu CC, Wu RS and Chung JG: Suppression of cell invasion and migration by propofol are involved in down-regulating matrix metalloproteinase-2 and p38 MAPK signaling in A549 human lung adenocarcinoma epithelial cells. Anticancer Res 32: 4833-4842, 2012.

53. Li D, Wang C, Li N and Zhang L: Propofol selectively inhibits nuclear factor-kappaB activity by suppressing p38 mitogen-activated protein kinase signaling in human EA.hy926 endothelial cells during intermittent hypoxia/reoxygenation. Mol Med Rep 9: 1460-1466, 2014

54. Hsu CP, Lin CH and Kuo CY: Endothelial-cell inflammation and damage by reactive oxygen species are prevented by propofol via ABCA1-mediated cholesterol efflux. Int J Med Sci 15: 978-985, 2018.

55. Chen L, Yang G and Dong H: Everolimus reverses palbociclib resistance in ER+ human breast cancer cells by inhibiting phosphatidylinositol 3-Kinase(PI3K)/Akt/mammalian target of rapamycin (mTOR) pathway. Med Sci Monit 25: 77-86, 2019.

56. Barra F, Evangelisti G, Ferro Desideri L, Di Domenico S, Ferraioli D, Vellone VG, De Cian F and Ferrero S: Investigational $\mathrm{PI} 3 \mathrm{~K} / \mathrm{AKT} / \mathrm{mTOR}$ inhibitors in development for endometrial cancer. Expert Opin Investig Drugs 28: 131-142, 2019.

57. Hu M, Zhu SX, Xiong SW, Xue XX and Zhou XD: MicroRNAs and the PTEN/PI3K/Akt pathway in gastric cancer (Review). Oncol Rep 43: 1439-1454, 2019

58. Hsing $\mathrm{CH}$, Chen YH, Chen CL, Huang WC, Lin MC, Tseng PC, Wang CY, Tsai CC, Choi PC and Lin CF: Anesthetic propofol causes glycogen synthase kinase-3beta-regulated lysosomal/mitochondrial apoptosis in macrophages. Anesthesiology 116: 868-881, 2012.

59. Sun X, Gu J, Chi M, Li M, Lei S and Wang G: Activation of PI3K-Akt through taurine is critical for propofol to protect rat cardiomyocytes from doxorubicin-induced toxicity. Can J Physiol Pharmacol 92: 155-161, 2014.

60. Padmanabhan A, Frangopoulos C and Shaffer LET: Patient satisfaction with propofol for outpatient colonoscopy: A prospective, randomized, double-blind study. Dis Colon Rectum 60: 1102-1108, 2017 